\title{
Tradición e innovación en la comunicación social: la experiencia inicial de Televisión Española
}

\author{
Natividad Cristina CARRERAS LARIO \\ Universidad de Sevilla \\ cristina@us.es
}

Recibido: $20 / 11 / 2012$

Aceptado: 23/01/2013

\begin{abstract}
Resumen
La televisión nació en España como extensión de la red de radiodifusión, fuertemente vigilado por la administración franquista. El poder político intuyó en el nuevo medio un nuevo recurso a su disposición para difundir y afianzar su doctrina. Sin embargo, debido al carácter comercial y de entretenimiento del nuevo medio, la televisión cambió los hábitos comunicativos de la sociedad española, introduciendo una mentalidad abierta al presente, desentendida de los valores sociales tradicionales.
\end{abstract}

Palabras clave: televisión española, franquismo, comunicación, programación, cambio social, modernización.

\section{Tradition and Innovation in Social Communication: The Initial Experience of Spanish Television (TVE)}

\begin{abstract}
Television was born in Spain as an extension of the regime radio broadcasts they were so tightly observed by the Franco Administration. Political power saw in this new medium a mechanism capable of helping to solidify its doctrines. However, the commercial and entertainment elements inherent in the broadcasts changed the communicative habits of Spanish society, fostering a mentality that was much more open to the present, a mentality ever distancing itself from traditional social values.

Keywords: Spanish television, Franco regime, communication, programming, social change, modernization

\section{Referencia normalizada}

CARRERAS LARIO, Natividad C. (2013): “Tradición e innovación en la comunicación social: la experiencia inicial de Televisión Española". Estudios sobre el mensaje periodístico. Vol. 19, Núm. especial abril, págs.: 671-679. Madrid, Servicio de Publicaciones de la Universidad Complutense.
\end{abstract}

Sumario: 1. Introducción. 2. Fuentes y metodología. 3. Marco institucional y desarrollo comercial. 4. La construcción de la audiencia: soportes de la programación. 5. Contenidos: entre propaganda y entretenimiento. 6. Conclusiones. 7. Referencias bibliográficas.

\section{Introducción}

En los años 50 la televisión se había asentado como principal medio de comunicación en las sociedades del entorno cultural español, acogiéndose a una regulación estatal países democráticos europeos encaminados hacia un Estado Social de Derecho- o a una concepción liberal capitalista renuente a la regulación administrativa, propia de la sociedad norteamericana (Faus, 1995). El régimen autárquico del general Franco no podía dar espaldas al nuevo medio, si pretendía desarrollarse al compás de los tiempos. Pero el sistema político español no respondía a ninguno de los países de su entorno. Se mantenía en una autarquía proteccionista, sin reconocimiento en el concierto de las naciones. El Régimen necesitaba la televisión. Como medio moderno y característico de la sociedad liberal capitalista, al ser portador de la ideología de la sociedad de masas, 
podía ser la televisión un instrumento muy valioso para el franquismo, que justo en esos momentos agotaba las posibilidades del modelo nacional-sindicalista, autárquico y proteccionista, y buscaba nuevos modelos en que apoyar su credibilidad.

Para una sociedad agotada de tanta historia y tanta introspección, la televisión abrió, al igual que el turismo, una ventana seductora al mundo, y así se tornó un poderoso dinamizador de las costumbres sociales, un espejo de las contradicciones morales y sociológicas de que se nutría la identidad nacional, un formidable transformador de los hábitos y costumbres cotidianas.

En el fondo intangible de la pequeña pantalla coincidieron, en pugna por la imposición social, falangistas, militares y eclesiásticos -por un lado, como elementos sustentadores de la tradición-; y escritores, artistas, pero sobre todo patrocinadores comerciales y la ficción norteamericana -por otro, que sembraron la semilla de la sociedad de consumo-.

\section{Metodología y fuentes}

El presente estudio se basa en una investigación empírica que reconstruye la programación inicial de Televisión Española (Carreras, 2012). Los datos fueron recogidos de fuentes variadas y dispersas, dada la inestabilidad de los documentos audiovisuales de la época y la impermeabilidad de los archivos de TVE. La fuente principal ha sido la revista Tele-Radio, órgano oficial de TVE, cuya colección completa se encuentra en la Biblioteca Nacional de España. Sobre esta fuente cabe suponer un margen de error con respecto a la emisión televisiva real, dado que la programación se anunciaba con un margen de antelación de varios días. En algún caso, fuentes secundarias, y posteriores a la emisión, han venido a refrendar esta sospecha, pero siempre como un factor excepcional. Del minucioso rastreo de la publicación, completado y contrastado con otras fuentes documentales secundarias, se ha procedido a reconstruir semana a semana las parrillas de programación, desde el año 1958 hasta el año 1962, en que con el relevo del ministro Arias Salgado por Manuel Fraga se puede dar con concluida la etapa fundacional de la televisión pública española. Dichas parrillas se pueden consultar en la obra anteriormente referida (Carreras, 2012).

La fase de la investigación que ahora se presenta tiene que ver con la interpretación y la valoración de los datos. Dada la complejidad que tal estudio interpretativo entraña, en que han de ser cruzados datos de programación, de horarios, de audiencias y de consumo, nos contentamos con ofrecer ahora, en el poco espacio disponible un adelanto del análisis y las conclusiones.

\section{Marco institucional y desarrollo comercial}

Arias Salgado al inaugurar TVE, el 28 de octubre de 1956, proclamó que los pilares de la programación habían de ser "el rigor y la ortodoxia religiosa y moral, así como el servicio a los principios fundamentales y a los grandes ideales del Movimiento Nacional" (García Jiménez, 1980: 234). Pero a pesar de esta declaración, no existía una noción clara del alcance sociológico de la televisión. Quizá no se viera más allá de que se trataba de un nuevo medio de comunicación social, que debía estar controlado políticamente. Las medidas institucionales de control fueron según Carreras, en térmi- 
nos generales, las siguientes: La censura, tanto política como moral, que acompañó a TVE durante toda su andadura hasta el advenimiento de la democracia. El Monopolio y centralismo en todo el proceso televisivo. Toda la programación era producida desde la propia televisión, en Madrid, primero, y después también en Barcelona. El aislamiento: TVE nació y se mantuvo durante muchos años aislada del resto de las televisiones europeas. La integración en Eurovisión se efectuó en diciembre de 1960. El control legislativo consistía en una ampliación de la normativa radiofónica. (Carreras 2012: 438) Desde el principio se hace patente la contradicción entre el carácter público de la televisión y el establecimiento de una programación en buena medida determinada por patrocinadores privados.

El gran esfuerzo de expansión de Televisión Española se pudo llevar a cabo, en un primer momento, gracias a las fuertes inversiones del Estado; pero a partir de 1958, fueron las inversiones publicitarias las que permitieron a TVE la consolidación de un horario de emisión y la creación de una red. Agentes de la industria publicitaria cuantifican su aportación entre un sesenta y un ochenta por ciento. El Estado percibía varios impuestos provenientes de la televisión: un impuesto de lujo directo por la venta de receptores, un canon por su utilización, y un impuesto sobre la publicidad televisada. El control del gasto público que se propuso a través de Plan de Estabilización de 1959 impedía cualquier implicación directa en los gastos de la televisión. Ésta, sin ningún sistema de financiación, tuvo -como se ha dicho- que recurrir a la publicidad. Sólo se incluían en los presupuestos generales del Estado partidas destinadas a hacer frente a los proyectos inmediatos del Plan Nacional de Televisión, unos sesenta y seis millones de pesetas destinados a las emisoras de Valencia, Zaragoza y Guadarrama como recoge Palacio (Palacio 2001: 35-36).

\begin{tabular}{|c|r|}
\hline CUADRO DE INGRESOS DE PUBLICIDAD $^{1}$ \\
\hline AÑO & CANTIDAD EN PESETAS \\
\hline 1958 & 4.440 .203 \\
\hline 1959 & 16.340 .974 \\
\hline 1960 & 33.830 .856 \\
\hline 1961 & 84.912 .124 \\
\hline 1962 & 212.899 .009 \\
\hline 1963 & 521.267 .954 \\
\hline
\end{tabular}

Según Vázquez Montalbán (1973: 40) la publicidad se fue convirtiendo en la primera fuente de financiación, más aún al ir ampliando la red por toda la península, hasta que llega un momento en que no sólo se autofinancia a través de la publicidad, sino que presentaba superávit.

\section{La construcción de la audiencia: soportes de la programación}

Los contenidos de la programación de TVE respondían a la escasa capacidad tecnológica de producción y emisión, a las precarias posibilidades económicas de la institución y al buen ojo de los programadores. Con un doble control: ideológico y sobre todo moral. En aquellos momentos, para Televisión Española, programar era, en buena medida llenar con el material disponible unas horas de emisión de la única cadena existente en el país. El programador no necesitaba conocer ni la audiencia, carecía además de instrumentos para medirla. A diferencia de hoy, en aquellos años podía

1 M. Vázquez Montalbán, El libro gris de Televisión Española, Madrid, Ediciones 99, 1973, pág. 41. 
ofrecer al público casi sin riesgos cualquier cosa, dada la novedad del producto, y la fascinación que provocaba en el receptor. La competencia, por otra parte, no existía. El desinterés inicial de los diversos grupos o familias del Régimen por la televisión, favorecía que los profesionales pudieran actuar con cierta autonomía, dentro, desde luego, de los controles ya señalados (Vila San Juan, 1981).

En la idea de Contreras y Palacio (2001), ya en estos primeros tiempos se puede cómo se va decantando un sentido de programación, superando inexperiencias, improvisaciones y limitaciones: la programación sedimenta poco a poco los intereses heterogéneos que inciden en ella (posibilidades técnicas y económicas, hábitos receptivos, horarios, escasa preparación profesional, influencia de los patrocinadores, directrices políticas o religiosas) hasta formar una estructura que, pese a carecer del control de las encuestas de audiencia, va formando un público. De ahí su importancia, porque, pese a la relativa falta de planificación racional, la programación responde a la idiosincrasia de la sociedad.

La programación evoluciona desde las tres horas diarias de emisión nocturna, en octubre de 1956, a la apertura de una segunda franja de sobremesa en 1958. En 1959 se incorpora una tercera franja horaria, la educativa, de 19,00 a 20,00. Cada franja se destinaba un sector característico de la audiencia. El Telediario articula ya de modo claro las franjas horarias más importantes; de sobremesa y nocturna. A partir de 1958 Televisión Española dejó de tomarse vacaciones y continuó su programación en verano. A la entrada del otoño se variaba la programación para la nueva temporada. La consolidación de la programación se advierte en 1962 al estabilizarse los horarios y prolongarse la duración de los programas.

\section{Contenidos: entre propaganda y entretenimiento}

Bajo el concepto de propaganda subsumimos, a efectos de la comparativa final, los contenidos informativos y los puramente ideológicos, a los que tan dada fue la televisión primera del Régimen franquista. En entretenimiento, los programas dramáticos, los filmados y los programas de variedades y concursos; dejamos fuera de consideración otras categorías, como programas educativos, infantiles, deportivos, y otros varios, aun a sabiendas que en éstas, como en las anteriores categorías, la impregnación política -y aún más que política: moral- es prácticamente inevitable. Queda asimismo fuera de la observación y del análisis la publicidad emitida, mucho más difícil de medir en tiempo y de conocer, dado que no se conservan documentos -cuñas vivase incluso se colaba indirectamente en programas de otra índole. ${ }^{2}$

El Telediario aparece en TVE a los pocos meses de su fundación, a principios de 1957, aunque apenas se disponen de datos hasta 1958. No cabe duda de que se trata del programa de mayor trascendencia política y clave del control ideológico que desciende sobre la población. La importancia del Telediario depende entre otros factores, de su cadencia, del estilo informativo, de la fascinación audiovisual que desencadena en el espectador, y del bajo nivel cultural de la mayoría de la población.

2 Véanse los datos recogidos sobre tarifas publicitarias en Carreras Lario, Natividad, TVE en sus inicios. Estudio sobre la programación, Madrid, Fragua, 2012, págs. 86-87 
A los telediarios se añaden otros programas informativos propagandísticos pero mucho menos influyentes. Es el caso de los que se centran, con periodicidad semanal, en la información castrense, como Riesgo y ventura del mundo, o Vuelta de horizonte. Son programas significativos porque aseguran la voz pública de una de las instituciones básicas del Régimen, el Ejército.

Otros programas de importancia desde el punto de vista ideológico, o simplemente de valor político-doctrinal para el franquismo, eran los comentarios que por ser de actualidad deben reseñarse entre los informativos. Entre ellos merece destacarse Con la verdad por delante de Jesús Suevos Fernández-Jové, o el Punto de vista eran comentarios de política nacional emitidos inmediatamente después de la primera edición de Telediario. Este tipo de programas, parecen favorecer sobre todo la línea de impronta falangista, tercer punto de apoyo del franquismo. Eran comentarios generalmente muy breves, bien escritos, pero con intención política demasiado evidente.

Hay que reseñar en este apartado finalmente, las retransmisiones. Estas, según Pérez Calderón (1965: 19), eran "el último peldaño en la escala de lo informativo". Algunas tenían una dimensión estrictamente política, como las que suceden en fechas conmemorativas del Régimen (desfiles militares y actos políticos), otras se refieren a acontecimientos deportivos y culturales. Estas últimas eran ideológicamente más eficaces que las primeras. No sólo porque gozaran de mayor audiencia, sino porque promovían ideas que eran beneficiosas para la revitalización del Régimen: apertura al exterior y mitos nacionales.

Entre los programas de entretenimiento cabe destacar los programas de variedades, concursos, telefilmes y anuncios publicitarios, donde juegan un papel muy destacado las empresas patrocinadoras.

El mayor impacto lo causaron los telefilmes que de un modo u otro impugnaban las restricciones morales y las estrecheces ideológicas del franquismo, a la vez que proponían un nivel de comodidad y consumo con el que no podían competir las mejoras sociales de las que presumía el Régimen. Y los telefilmes abundaban y se multiplicaban, posiblemente por razones económicas (su coste era más barato que la producción propia) y políticas, puesto que el potencial de evasión que poseían apartaría al espectador de otras preocupaciones. Desde 1959, son las estrellas de la programación, emitiéndose unos doce a la semana. Fuera por estas razones o por otras, lo cierto es que Patrulla de tráfico, Te quiero Lucy, que comienza a emitirse en 1958, o Perry Mason, obtienen la aceptación suficiente como para permanecer en la programación y regresar a ella una y otra vez.

Tal vez el éxito de este tipo de espacios impulsó a la realización propia de series de programas breves que, como los de Jaime de Armiñán, suponían un nuevo señuelo para las clases medias. El cine español de la época oscilaba entre los alegatos político, un neorrealismo generalmente trágico y comedias ligeras, casi siempre demasiado superficiales, a excepción de las de Berlanga (Calabuch, 1956; Plácido, 1961; El Verdugo, 1963) que, sin embargo, contenían siempre un nivel crítico para exponer el patetismo de la situación social española. En contraste con estos discursos, trabajos como los de Armiñán reproducían la cotidianidad de las capas medias, especialmente las femeninas, en reflejo que podía tener como consecuencia la aspiración a un modo de vida diferente. 
Los programas de variedades tuvieron una amplia presencia en estos primeros años. Junto a los concursos constituían el formato preferido por los patrocinadores, de ahí que ocuparan en los primeros años muchas horas y en horario de máxima audiencia, durante los fines de semana. Eran sencillos de producir y contaban fácilmente con patrocinio. Al evolucionar la televisión, fueron perdiendo el aire radiofónico y pasaron a ocupar menos horas, pero ganaron en calidad. Así ocurrió con Gran Parada, que arrancó en octubre de 1959. Un año después surgieron programas más televisivos como La tortuga perezosa, Los amigos del martes o Escala en Hi-Fi.

Los concursos, al principio integrados en programas de entretenimiento, se fueron consolidando poco a poco, quizá porque interesaban a patrocinadores, que les atribuían una alta audiencia. En general tenían buenas dosis de espectacularidad.

Sin duda los programas, digamos, cultos, como los centrados en el teatro o en la difusión del libro, sirvieron para dar a conocer muchas claves de las inquietudes europeas de la alta cultura de la época, pero los programas a los que ahora nos referimos garantizaban sin duda alguna, la presencia inicial de la nueva cultura popular $\mathrm{o}$, si se prefiere, de la baja cultura ( Horkheimer y Adorno, 2007 ), o, sencillamente, de lo que ya en estos años se conocía como cultura pop (que examinaban los británicos del Independent Group, los franceses conocidos como décollagistes y los artistas pop norteamericanos) en la arquitectura cultural aparentemente ciclópea del franquismo. $\mathrm{Ni}$ la cultura del miedo ni la propaganda de las instituciones (que empezaban a parecer algo rancias) ni los cantos al paisaje patrio podían competir con semejantes novedades.

Pueden estudiarse, a continuación, los cuadros relativos a la programación televisiva de la que se poseen datos fidedignos (enero de 1958) y la última del período que ha constituido objeto de observación (julio de 1962), cuantificados en horas emitidas según géneros:

Tabla 1: Enero de 1958

\begin{tabular}{|l|c|c|}
\hline GÉNEROS & MINUTOS & HORAS \\
\hline Dramáticos & 210 & $03: 30$ \\
\hline Informativos & 355 & $05: 55$ \\
\hline Filmados & 285 & $04: 45$ \\
\hline Variedades y concursos & 335 & $05: 35$ \\
\hline Infantiles & 204 & $03: 24$ \\
\hline Educativo culturales & 185 & $03: 05$ \\
\hline Varios & 185 & $03: 05$ \\
\hline TOTAL MENSUAL & $\mathbf{1 . 7 5 9}$ & $\mathbf{2 9 : 1 9}$ \\
\hline
\end{tabular}

\begin{tabular}{|l|c|c|}
\hline GÉNEROS & MINUTOS & HORAS \\
\hline Dramáticos & 255 & $04: 15$ \\
\hline Informativos & 828 & $13: 48$ \\
\hline Filmados & 410 & $06: 50$ \\
\hline Variedades y concursos & 400 & $06: 40$ \\
\hline Infantiles & 330 & $05: 30$ \\
\hline Educativo culturales & 145 & $02: 25$ \\
\hline Varios & 422 & $07: 02$ \\
\hline TOTAL MENSUAL & $\mathbf{2 . 8 1 0}$ & $\mathbf{4 6 : 3 0}$ \\
\hline
\end{tabular}

En cinco años y medio la programación incrementa en algo más de diecisiete $(17,11)$ las horas de programación. Los programas informativos, que en enero de 1958 representaban el 19\% del total de horas emitidas, incrementan progresivamente su producción hasta alcanzar el 29\% en el mes de julio de 1962. La lectura de los datos puede interpretarse en dos sentidos: la aparición de la televisión como medio infor- 
mativo crea necesidad de información en la sociedad española, alcanzando transversalmente a amplios sectores de la población, pero muy particularmente a aquellos sectores que poco - por medio de la radio- o nada se habían asomado al conocimiento de la actualidad. Podría decirse que la curiosidad acaba produciendo necesidad en los hábitos de la audiencia. Y esto concluye con una elevación del nivel cultural y de la conciencia política. Pero asimismo puede entenderse como la conciencia adquirida en los dirigentes franquistas del potencial insospechado de la televisión como medio de propaganda. De la improvisación inicial, cuando se creía que el medio de influencia dominante seguiría siendo la radio, se pasaría a la conciencia constatada de la eficacia del medio televisivo para crear audiencia y penetrarla ideológicamente. La información se habría de controlar así como propaganda, y el efecto provocado en la audiencia sería el de la desinformación.

Frente al incremento observado en los informativos, los programas de entretenimiento evolucionan de la siguiente manera: los filmados, que comprenden documentales, películas, y telefilmes, evolucionan de un $15,2 \%$ inicial, a un $14 \%$ último. En este apartado, conforme se va imponiendo el sentido industrial en la producción televisiva, se retiran los documentales y películas en favor del incremento de telefilmes norteamericanos. Convendría dejar apuntado aquí que la evolución observada obedece tanto al éxito de público como al establecimiento de relaciones comerciales entre Norteamérica y España, que el general Franco pone al servicio de la estrategia militar norteamericana. La regulación administrativa de 1958 libera la importación de telefilmes, y al año siguiente se pueden seguir semanalmente entre lunes y viernes, en prime time, hasta doce series distintas de importación (Castro de Paz, 1999). De enemiga tradicional de España, Norteamérica pasa a convertirse en seductora tierra de entretenimiento y modernidad.

Los programas de variedades y concursos se acercaban en la primera época a la ratio de los informativos, alcanzando un $18,3 \%$ de la programación. Caen hasta el $13,8 \%$ en la última fecha. Esta evolución se debe a que los grandes patrocinadores, ante el incremento de la publicidad directa, se van inclinando por esta fórmula, se refugian en los programas de concursos que se escinden de los de variedades, y decaen en su interés por los costosos e imprevisibles programas ante el público.

Los programas dramáticos -se entiende aquí obras dramáticas y series guionizadas- en la primera programación ocupan el 11,3\% del total emitido, mientras al final del período se repliegan hasta el $8,9 \%$. La evolución, aunque pueda interpretarse negativamente, supone que el celo adoctrinador del emisor televisivo va perdiendo pulso ante el interés creciente de ofrecer obras universales realizadas con criterios de calidad dramática.

La visión global que arroja la comparativa indica que pese al crecimiento de los programas informativos y el relativo retroceso de otros géneros, éstos, en conjunto, acaban no solo por imponerse en la programación, sino que se convierten también en las señas de identidad del medio, y estructura la demanda de la audiencia. En términos absolutos podría concluirse que en la televisión el peso del Régimen se hacía menos asfixiante, y la mirada fija en la pequeña pantalla respiraba un aire de libertad contrastante con el gris ambiente de la vida española. 


\section{Conclusiones}

El modelo de televisión que cristalizó en España resultó un híbrido entre el modelo institucional, propio de los países europeos democráticos, y el comercial, que se había impuesto en Estados Unidos, a lo que había que añadir los afanes de fiscalización propios de un régimen dictatorial como el de la Alemania nacional-socialista.

El Régimen estaba interesado en la televisión, dado el precedente radiofónico, que tanto le había ayudado a imponerse. La radio era el gran entretenimiento nacional, la gran transmisora y creadora de la cultura popular en la España de los cincuenta, además de cumplir eficazmente como instrumento ideológico por medio del monopolio informativo. El franquismo acabó comprendiendo que la televisión se acabaría imponiendo a la radio, e intentó aprovecharse de ella para su perpetuación. Pero su visión obedecía más a principios ideológicos que a un conocimiento fundado en la sociología. La consideración sociológica del medio estaba en mantillas, y como se condiciona la programación a su financiación comercial, los valores de la nueva sociedad de consumo y de masas irrumpen con su pujante modernidad en los hogares españoles, enseñando otro mundo y otras posibilidades de entender la vida. Los espacios comerciales venden mejor que los políticos ante una audiencia fatigada de discursos, que ansía saborear los nuevos gustos que avizoran allende nuestras fronteras, en la pantalla del televisor. El modelo de una sociedad abierta y democrática, que exporta los modos de vida más sugerentes entonces, invade la pequeña mentalidad de la claustrofóbica sociedad española, por medio de los telefilmes.

La aparición de la televisión en España coincide con el proceso de desarrollismo económico y con la evolución de un modelo cultural elitista y dirigista hacia una cultura de masas que no genera acción política, pero sí una profunda transformación social. Por ello la televisión puede elevarse a signo paradójico del franquismo, condenado a modernizarse para perdurar, pero sembrando con esa misma modernización, de la que la televisión fue instrumento estratégico, las semillas de su propia destrucción.

\section{Referencias bibliográficas}

ADORNO, Teodor y HORKHEIMER, Max (2007): Dialéctica de la ilustración: fragmentos filosóficos. Madrid, Akal

BAGET HERMS, Josep Ma (1993): Historia de la televisión en España (1956-1975). Barcelona, Ediciones Feed Back

CARRERAS LARIO, Natividad C. (2012): TVE en sus inicios. Estudio sobre la programación. Madrid, Fragua.

CASTRO DE PAZ, José Luis (1999): El surgimiento del telefilme. Barcelona, Paidós Comunicación

CONTRERAS, José Miguel y PALACIO, Manuel (2001): La programación televisiva. Madrid, Síntesis

FAUS BELAU, Ángel (1995): La era audiovisual, Historia de los primeros cien años de la radio y la televisión. Pamplona, Ed. Internacionales Universitarias 
GARCÍA JIMÉNEZ, Jesús (1980): Radiotelevisión y política cultural en el franquismo. Madrid, CSIC

JULIÁ, Santos (1999) Un siglo de España: politica y sociedad. Madrid, Marcial Pons PALACIO, Manuel (2001): Historia de la televisión en España. Madrid, Gedisa. PÉREZ CALDERÓN, Miguel (1965): La televisión. Madrid, Editora Nacional.

TAMAMES, Ramón (2008): Estructura económica de España. Madrid, Alianza (25ำ ed.)

VÁZQUEZ MONTALBÁN, Manuel (1973): El libro gris de televisión. Ediciones 99, Madrid.

VILA SAN-JUAN, Juan Felipe (1981): La trastienda de TVE. Barcelona, Plaza y Janés

\section{Natividad Cristina CARRERAS LARIO}

Departamento de Comunicación

Colaboradora doctora

Universidad de Sevilla

cristina@us.es 